\title{
LARRA, PERIODISTA URUGUAYO
}

Gregorio Cervantes Martin

Hace casi diez años, en un homenaje que la Revista de Occidente dedicó a Larra, escribía Osvaldo Álvarez Guerrero lo siguiente: "España en Hispanoamérica, no había sido aún vencida. España representaba un pasado que no había sido superado todavía en Hispanoamérica, porque no había sido superado en la propia España ... y entonces acaecía que Larra y las generaciones hispanoamericanas que eran sus contemporáneos luchaban por lo mismo." "Notaba también que Larra y los intelectuales del Río de la Plata pertenecían a una misma generación con elementos culturales, sociales y económicos muy semejantes, y - después de referirse a los artículos de Alberdi en La Moda citaba de un artículo que Sarmiento escribiera en El Mercurio (Santiago de Chile) en 1841: "Larra ha introducido en su país y creado a un tiempo, un género de literatura que por todas partes se esfuerzan en imitar y que hace de sus escritos un legado y un patrimonio para los pueblos que hablan la lengua castellana, a cuyas costumbres y necesidades se adaptarían maravillosamente (. . .) . . somos una segunda, tercera o cuarta edición de la España. Sus vicios son los mismos de que adolecemos nosotros, hijos de tal madre; nuestras costumbres no le van a la zaga. Así que lo que allá se ha escrito, nos vendrá siempre de perlas."

Esa influencia de Larra ha sido repetidas veces mencionada y estudiada en numerosos trabajos, principalmente con motivo del centenario de su muerte. ${ }^{3}$ José Antonio Oría publicó por entonces un extenso artículo, “Alberdi 'Figarillo.' Contribución al estudio de la influencia de Larra en el Río de la Plata," Humanidades, XXV (1936), 223-83, en el que estudiaba la relación entre Larra y Alberdi, y notaba la publicación en Buenos Aires de un periódico titulado Fígaro, que terminó con su primer número el 3 de octubre de $1833 .^{4}$

Ya en 1831, antes por lo tanto que en Buenos Aires, se había anunciado en Montevideo la publicación de un periódico que habría de titularse Fígaro Ministerial. En El Indicador, número 44 (6 de agosto de 1831), periódico de cuatro páginas a tres columnas que costaba un real, se anuncia en la página cuatro, al principio de la columna de la izquierda y bajo "Avisos Nuevos," la publicación para el sábado 13 de "un nuevo periódico titulado el Figaro Ministerial," y se indica que "los SS. qae [sic] quieran subcribirse [sic] podrán hacerlo en la tienda de Mr. Gard, calle del portón.” El anuncio aparece otra vez en el siguiente número (lunes, 8 de agosto), misma página y columna, así como en los números 46, 47 (con el "que" ya bien escrito), 48 y 49 (misma página, columna de la derecha). En el número 50 (sábado, 13 de agosto), que era el día señalado en el anuncio de El Indicador para la aparición del primer número del Figaro Ministerial, ya no hay anuncio. Dejó también de anunciarse el 13 de agosto la publicación de otro 
nuevo periódico, pero volvió a anunciarse en el número 75 de El Indicador (viernes, 16 de setiembre de 1831) que el primer número de La Periódico Manía saldría ese mismo día. El martes 27 se anuncia el cuarto número para el día siguiente. ${ }^{5}$

El Fígaro de Montevideo tuvo, pues, menos suerte que el de Buenos Aires, ya que no llegó a publicar ni un solo número. Antonio Praderio menciona el anuncioy afirma no haber hallado ningún ejemplar de dicho periódico, ${ }^{6}$ pero esto prueba que "Fígaro" era bien conocido en el mundo de habla castellana como título de periódico o como personaje de la obra de Beaumarchais y de la de Rossini. ${ }^{7}$ No obstante, nadie lo usó como pseudónimo literario antes que Larra.

Queda por vez qué cambios sufría un artículo del madrileño para adaptarlo, como dice Sarmiento, a las costumbres y necesidades de las nuevas repúblicas americanas. Para ello tomaré como ejemplo el artículo "En este país," que Larra publicó en La Revista Española en abril de 1833, y que fue publicado en Montevideo en El Eco Oriental, número 13 (12 de agosto de 1835). Antes del título se dan las razones por las que se reproduce el artículo:

El siguiente rasgo que sacamos de un diario del año anterior, encierra ideas muy patrióticas, y por lo mismo creemos conveniente reproducirlo en nuestras páginas, porque hay ciertas cosas cuya oportunidad no pasa fácilmente, y la manía extrangera [sic] que esplica [sic] este artículo vemos con dolor que hace prosélitos aunque tan miserables como ella.

Es decir, las razones son que las ideas patrióticas que el artículo contiene, y que Larra escribiera para los españoles, valían también para los uruguayos, cada día más inclinados a favorecer todo lo que procediese de fuera.

En la reimpresión que hizo del artículo El Eco Oriental - teniendo en cuenta el orden en que aparecen - he notado los cambios siguientes:

Cambios en el número

Larra

escena

sonido vago

la causa

ascos

teatros

esfuerzos

\section{El Eco Oriental}

escenas

sonidos vagos

las causas

asco

teatro

esfuerzo

Cambios en el verbo

produjeran

pude

Llevóme

sabe

No entremos

cantado

vuelvan produjeron

puedo

puede

Llévame

saben

No entramos

cantándolo

vuelven 
Cambios ortográficos

Larra

$$
\begin{aligned}
& \text { ansioso } \\
& \text { circunstancias } \\
& \text { extraños } \\
& \text { explicaciones } \\
& \text { explicarle } \\
& \text { atraso } \\
& \text { atrasados } \\
& \text { expresión }
\end{aligned}
$$

Sustituyamos

quiso

viajes

excusa

cocinero

exquisito

beefsteak

ocho o diez

appartement

a pesar

exclamaba

extranjero -s

cafés

vilipendiar

descritas

acerca

El sí de las niñas

Hijo Pródigo

Marlborough

Mambruc

que en

explicar

extrañamos

\section{El Eco Oriental}

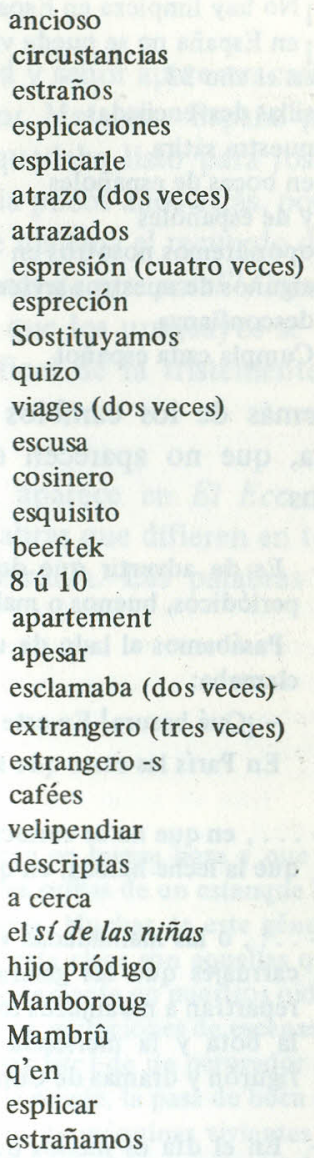

Palabras que han sido reemplazadas por otras o suprimidas

los términos

extirparla

Don Periquito -s

Carabanchel

ni más mundo que el

salón del Prado

su muebles y sus ropas

en una casa de huéspedes

España

¿ Lo ve usted, Fígaro? las orillas

interpretarla

D. Exequiel -es (nueve veces)

Matanza

Suprimido en $\mathrm{El} \mathrm{Eco}$

sus muebles y ropas

en casa de huéspedes

aquí (cuatro veces)

¿ Lo ve Vd.? 


\section{Larra}

Diario de los Debates

Times

¡ No hay limpieza en España!

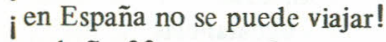

en el año 33

sillas desvencijadas

nuestra sátira

en bocas de españoles

y de españoles

opondremos nosotros en

algunos de nuestros artículos

desconfianza

Cumpla cada español

\section{El Eco Oriental}

Monitor

Imparcial

¡No hay limpieza en este país!

en este país no se puede viajar!

en el año 34

sillas de baquetas

nuestra saliba

en bocas de Americanos

y de Americanos

opondremos en algunos de

nuestros artículos

confianza

Cumpla cada americano

Además de los cambios de acentuación, puntuación y de palabras o frases en bastardilla, que no aparecen en el artículo de Larra, los siguientes párrafos han sido suprimidos:

A - Es de advertir que don Periquito no sabe francés ni inglés, y que en cuanto a periódicos, buenos o malos, en fin, los hay, y muchos años no los ha habido.

Pasábamos al lado de una obra de eses que hermosean continuamente este país, y clamaba:

- ¡Qué basura! En este país no hay policia.

En París las casas que se destruyen y reedifican no producen polvo.

B - . . en que no se conocía en la Corte más botillería que la de Canosa, ni más bebida que la leche helada; en que no había más caminos en España que el del cielo.

C - . . , o las malhadadas ventas oara caminantes asendereados; en que no corrían más carruajes que las galeras y carromatos catalanes; en que los chorizos y polacos repartían a naranjazos los premios al talento dramático, y llevaba el público al teatro la bota y la merienda para pasar a tragos la representación de las comedias de figurón y dramas de Comella.

D - En el día es menos que nunca acreedor este país a nuestro desprecio. Hace años que el Gobierno, granjeándose la gratitud de sus súbditos, comunica a muchos ramos de prosperidad cierto impulso benéfico, que ha de completar por fin algún día la grande obra de nuestra regeneración. ${ }^{8}$

Hay puntos suspensivos antes de la omisión A, pero no antes de C o B. Se enlaza lo que las precede con lo que las sigue sin indicar omisión alguna. Es fácil de comprender la falta de C. La lamentable situación del teatro español, con chorizos y polacos luchando a naranjazos durante las representaciones, no era fácil de igualar. Hasta cierto punto es comprensible también la omisión de B por los lugares citados; pero A y D me parece que hubieran encajado perfectamente dentro de la situación uruguaya. Bastaba sustituir en D "regeneración" por "independencia". Lo que Larra dice en A de los periódicos de España pudiera decirse en 1835 de los del Uruguay. El primer periódico que se publicó en Montevideo fue La Estrella del Sur, escrito en inglés y castellano, que permaneció en circulación de mayo a julio de 1807. Después, algunos años hubo periódicos y otros no, 
hasta que comenzaron a publicarse con regularidad a partir de 1821. En 1834, que es la fecha que figura en el artículo aquí estudiado, y 1835, que es cuando apareció en El Eco, en Montevideo se publicaron hasta ocho periódicos, algunos procedentes de años anteriores.

Como hemos visto, los cambios eran mínimos - usted y señor aparecen casi siempre en la forma abreviada. Bastaba sustituir Carabanchel por Matanza, España por aquí, españoles por americanos, etc. y el artículo de Larra quedaba listo para los lectores uruguayos. Una nación que había ganado su independencia pocos años atrás, podía decir como Fígaro: "Sustituyamos sabiamente a la esperanza de mañana el recuerdo de ayer, y veamos si tenemos razón en decir a propósito de todo: ; Cosas de este pais!" Comparar un pasado de coloniaje con un presente de libertad era para que los uruguayos se sintieran felices, como decía el mismo Fígaro a los españoles al final de la tristemente célebre década de Fernando VII.

Reproduzco a continuación el artículo tal como aparece en El Eco Oriental, número 13, 12 de agosto de 1835. En negrita están las palabras que difieren en todo o en parte del trabajo de Larra, salvo las que están en bastardilla. Las palabras y frases suprimidas van entre corchetes.

\section{EN ESTE PAIS}

Hay en el lenguaje vulgar frases afortunadas que nacen en buena hora y que se derraman por toda una nación, así como se propagan hasta las orillas de un estanque las ondas producidas por la caida de una piedra en medio del agua. Muchas de este género pudieramos citar en el vocabulario político sobre todo; de esta clase son aquellas que halagando las pasiones de los partidos han resonado tan funestamente en nuestros oidos en los años que ván [sic] pasados de este siglo, tan fecundo en mutaciones de escenas y en cámbio [sic] de decoraciones. Cae una palabra de los lábios [sic] de un perorador en un pequeño círculo, y un gran pueblo, ancioso de palabras, la recoje, la pasa de boca en boca, y con la rapidez del golpe eléctrico un crecido número de máquinas vivientes la repite y la consagra, las mas veces sin entenderla, y siempre sin calcular que una palabra sola es á veces palanca suficiente á levantar la muchedumbre, inflamar los ánimos y causar en las cosas una revolucion.

Estas voces favoritas han solido siempre desaparecer con las circustancias que las produjeron. Su destino es efectivamente, como sonidos vagos que son, perderse en la lontananza conforme se apartan de las causas que las hizo nacer. Una frase, empero, sobrevive siempre entre nosotros, cuya existencia es tanto mas dificil de concebir cuanto que no es de la naturaleza de esas de que acabamos de hablar, estas sirven en las revoluciones á lisonjear á los partidos, y á humillar á los caidos, objeto que se entiende perfectamente, una vez conocida la generosa condicion del hombre; pero la frase que forma el objeto de este artículo se perpetúa entre nosotros, siendo solo un funesto padron de la ignominia para los que la oyen y para los mismos que la dicen: así la repiten los vencidos como los vencedores, los que pueden como los que no quieren interpretarla; los propios, en fin, como los estraños.

En este país..........esta es la frase que todos repetimos á porfia, frase que sirve de clave para toda clase de esplicaciones; cualquiera que sea la cosa que á nuestros ojos choque en mal sentido. ¿Qué quiere $V d$, decimos, en este pats? Cualquier aconte- 
cimiento desagradable que nos suceda, creemos esplicarle perfectamente con la frasecilla ¡cosas de este pais! [frasecilla: ¡Cosas de este país!] que con vanidad pronunciamos y sin pudor alguno repetimos.

¿Nace esta frase de un atrazo reconocido en toda la nación? No creo que pueda ser este su origen, porque solo puede conocer la carencia de una cosa, el que la misma cosa conoce; de donde se infiere que si todos los individuos de un pueblo conociesen su atrazo, no estarían realmente atrazados? [sic] Es la pereza de imaginacion ó de raciocinio que nos impide investigar la verdadera razon de cuanto nos sucede, y que se goza en tener una muletilla siempre á mano con que responderse á sus propios argumentos, haciéndose cada uno la ilusión de no creerse cómplice de un mal, cuya responsabilidad descarga sobre el estado del país en general? Esto parece mas ingenioso que cierto.

Creo entrever la causa verdadera de esta humillante espresion. Cuando se halla un país en aquel crítico momento en que se acerca á una transicion, y en que saliendo de las tinieblas comienza á brillar á sus ojos un ligero resplandor, no conoce todavia el bien, empero ya conoce el mal de donde pretende salir para probar cualquiera otra cosa que no sea lo que hasta entonces ha tenido. Sucédele lo que á una jóven [sic] bella que sale de la adolescencia, no conoce el amor todavia ni sus goces; su corazon sin embargo, ó la naturaleza por mejor decir, le empieza á revelar una necesidad, que pronto será urgente para ella, y cuyo germen y cuyos medios de satisfaccion tiene en sí misma, si bien los desconoce todavia, la vaga inquietud de su alma, que busca y ánsia [sic] sin saber, que la atormenta y la disgusta de su estado actual y del anterior en que vivia; y vésela despreciar y romper aquellos mismos secillos juguetes que formaban poco antes el encanto de su ignorante existencia.

Este es acaso nuestro estado, y este á nuestro entender el orígen [sic] de la fatuidad que en nuestra juventud se observa: el medio saber reina entre nosotros; no conocemos el bien, pero sabemos que existe y que podemos llegar á poseerle, si bien sin imaginar aun el cómo, [sic] Afectamos, pues, hacer asco de lo que tenemos para dar á entender á los que nos oyen que conocemos cosas mejores, y nos queremos engañar miserablemente unos a otros, estando todos en el mismo caso.

Este medio saber nos impide gozar de lo bueno que realmente tenemos, y aun nuestra ánsia [sic] de obtenerlo todo de una vez, nos ciega sobre los mismos progresos que vamos insensiblemente haciendo.

Estamos en el caso del que teniendo apetito desprecia un sabroso almuerzo con la esperanza de un suntuoso convite incierto, que se verificará, ó no se verificará mas tarde. Sostituyamos sábiamente á la esperanza de mañana el recuerdo de ayer, y véamos [sic] si tenemos razon [sic] en decir á propósito de todo: - jCosas de este país!

Solo con el auxilio de las anteriores reflexiones puedo conocer el carácter de $\mathbf{D}$. Exequiel, ese petulante jóven [sic], cuya instrucción [sic] está reducida al poco latin que le quisieron enseñar y que él no quizo aprender; cuyos viages no han pasado de la Matanza; que no lée [sic] sino en los ojos de sus queridas, los cuales no son ciertamente los libros mas filosóficos; que no conoce, en fin, mas ilustracion [sic] que la suya, mas hombres que sus amigos, cortados por la misma tijera que él, [ni más mundo que el salón del Prado] ni mas país que el suyo. Este fiel representante de gran parte de nuestra juventud desdeñosa de su país, fue no ha mucho tiempo objeto de una de mis visitas.

Encontrele en una habitacion mal amueblada y peor dispuesta, como de hombre solo; reinaba en sus muebles y [sus] ropas tiradas aquí y allí, un espantoso desórden [sic], de que hubo de avergonzarse al verme entrar.

"Este cuarto está hecho una leonera, me dijo: - ¿Qué quiere Vd? en este pais. . Y quedó muy satisfecho de la escusa que á su natural descuido había encontrado. 
Empéñose [sic] en que había de almorzar con él, y no puede resistir á sus instancias: un mal almuerzo, mal servido reclamaba indispensablemente algun nuevoachaque, y no tardó mucho en decirme: - Amigo, en este país no se puede dar un almuerzo á nadie; hay que recurrir á los platos comunes y al chocolate.

"Vive Dios, dije yo para mí, que cuando en este pais se tiene un buen cosinero y un esquisito servicio y los criados necesarios, se puede almorzar un excelente beeftek, con todos los adherentes de un almuerzo á la fourchette; y que en París los que pagan 8 ú 10 reales por un apartement garní, ó una mezquina habitación en [una] casa de huespedes, como mi amigo D. Exequiel, no se desayunan con pavos trufados ni con champagne.

Mi amigo Exequiel es hombre pesado como los hay en todos los paises, y me instó á que pasase el dia con él, y yo que habia empezado ya á estudiar sobre aquella máquina como un anatómico sobre un cadáver, acepté inmediatamente.

D. Exequiel es pretendiente apesar [sic] de su notoria inutilidad. Llévame, pues, de ministerio en ministerio; de dos empleos con los cuales contaba, habíase llevado el uno, otro candidato que habia tenido mas empeños que él -jCosas de aqui! me salió diciendo, al referirme su desgracia. Ciertamente, le respondí, sonriéndome de su injusticia, porque en Francia y en Inglaterra no hay intrigas; puede Vd. estar seguro de que allâ todos son unos santos varones, y los hombres no son hombres."

El segundo empleo que pretendia habia sido dado á un hombre de mas luces que él $-{ }_{j}$ Cosas de aqui! me repitió.

Sí; proque en otras partes colocan â los nécios [sic], dije yo para mí:

Llevóme en seguida á una librería, despues de haberme confesado que habia publicado un folleto, llevado del mal ejemplo. Preguntó cuantos ejemplares se habian vendido de su peregrino folleto, y el librero respondió: ni uno.

${ }_{i}$ Lo ve Vd [,Fígaro]? me dijo ${ }_{\zeta} l o$ ve Vd? En este país no se puede escribir. Aquí nada se vende, vejetamos en la ignorancia.

\section{En París hubiera vendido diez ediciones.}

Ciertamente, le contesté yo, porque los hombres como Vd. venden en París sus ediciones.

En París no habrá libros malos que no se lean, ni autores nécios [sic] que se mueran de hambre.

Desengáñese Vd. en este pats no se lée, prosiguió diciendo. Y Vd. que de eso se queja, Sr. D. Exequiel: Vd. ¿qué lée? le hubiera podido preguntar. Todos nos quejamos de que no se lée, y ninguno leemos.

¿Lée Vd. los periódicos, le pregunté sin embargo? [sic]

No señor, en este país no se saben escribir periódicos. ¡ Lea Vd. ese Monitor, ese Imparcial. . . . . . 9

[Es de advertir que don Periquito no sabe francés ni inglés, y que en cuanto a periódicos, buenos o malos, en fin, los hay, y muchos años no los ha habido.

Pasábamos al lado de una obra de esas que hermosean continuamente este país, y clamaba:

- ¡Qué basura! En este país no hay policía.

En París las casas que se destruyen y reedifican no producen polvo.] esclamaba.

Metió el pié [sic] torpemente en un charco ;No hay limpieza en este país!

En el extrangero no hay lodo. 
Se hablaba de un robo - ; Ah! país de ladrones! vociferaba indignado. Porque en Lóndres [sic] no se roba, en Lóndres [sic] donde en la calle acometen los malhechores á la mitad de un dia de niebla á los transeuntes.

Nos pedia limosna un pobre: $;$ En este país no hay mas que miseria! esclamaba horripilado. Porque en el extrangero no hay infeliz que no arrastre coche.

Ibámos [sic] al teatro, y ; Oh qué horror! decia mi D. Exequiel con compasion, sin haberlos visto mejores en su vida. ; Aqui no hay teatro!

Pasábamos por un café, no entramos. ; Que cafées los de este país! gritaba.

Se hablaba de viages. ¡Oh! Dios me libre: en este pais no se puede viajar! ¡Qué posadas! ¡Qué caminos! ¡O infernal comezon [sic] de velipendiar este país! que adelanta y progresa de algunos años á esta parte, mas rápidamente que adelantaron esos países modelos, para llegar al punto de ventaja en que se han puesto.

Porque los D. Exequieles que todo lo desprecian en el año 34, no vuelven los ojos á mirar atras, ó no preguntan á sus papás á cerca [sic] del tiempo que no está tan distante de nosotros, [en que no se conocía en la Corte más botillería que la de Canosa, ni más bebida que la leche helada; en que no había más caminos en España que el del cielo,] en que no existian mas posadas que las descriptas por Moratin en el st de las niñas con las sillas de baquetas y las estampas del hijo pródigo; [,o las malhadadas ventas para caminantes asendereados; en que no corrían más carruajes que las galeras y carromatos catalanes; en que los chorizos y polacos repartían a naranjazos los premios al talento dramático, y llevaba el público al teatro la bota y la merienda para pasar a tragos la representación de las comedias de figurón y dramas de Comella;] en que no se conocia mas ópera que el que el [sic] Manboroug (ó Mambrú como dice el vulgo) cantándolo á la guitarra; en que no se leia mas periódico que el diario de avisos, y en fin.....en qué. .....

Pero acabemos este artïculo [sic] demasiado largo para nuestro propósito; no vuelven á mirar atrás porque habrian de poner un término á su maledicencia, y llamar prodigiosa la casi repentina mudanza q'en este pais se ha verificado en tan breve espacio.

Concluyamos sin embargo, de esplicar nuestra idea claramente, mas que á los D. Exequieles que nos rodean pese y avergüence.

Cuando oimos á un extrangero que tiene la fortuna de pertenecer á un país donde las ventajas de la ilustracion se han hecho conocer con mucha anterioridad que en el nuestro, por causas que no es de nuestra inspeccion examinar, nada estrañamos en su boca, sino es la falta de consideracion y aun de gratitud que reclama la hospitalidad de todo hombre honrado que la recibe; pero cuando oimos la espresion despreciativa que hoy merece nuestra saliba, en boca de Américanos [sic], y de Américanos [sic] sobre todo que no conocen mas país que este mismo suyo que tan injustamente dilaceran, apenas reconoce nuestra indignacion limites en que contenerse.

[En el día es menos que nunca acreedor este país a nuestro desprecio. Hace años que el Gobierno, granjeándose la gratitud de sus súbditos, comunica a muchos ramos de prosperidad cierto impulso benéfico, que ha de completar por fin algún día la grande obra de nuestra regeneración.]

Borremos, pues, de nuestro lenguage la humillante espresion que no nombra á este país sino para denigrarle; volvamos los ojos atras, comparemos y nos creeremos felices. $\mathrm{Si}$ alguna vez miramos adelante y nos comparamos con el estrangero, sea para prepararnos un porvenir mejor que el presente: y para rivalizar en nuestros adelantos con los de nuestros vecinos. Solo en este sentido opondremos [nosotros] en algunos de nuestros artîculos [sic] el bien de fuera al mal de dentro.

Olvidemos, lo repetimos, esa funesta espresion que contribuye á aumentar la injusta confianza que de nuestras propias fuerzas tenemos. Hagamos mas favor ó justicia 
á nuestro país, y creámosle capaz de esfuerzo y felicidades. Cumpla cada américano [sic] con sus deberes de buen patricio, y en vez de alimentar nuestra inaccion con la esprecion de desaliento - ; Cosas de aqul! Contribuya cada cual á las mejoras posibles: entonces este païs [sic] dejará de ser tan maltratado de los estrangeros, á cuyo desprecio nada podemos oponer, si de él les damos nosotros mismos el vergonzoso ejemplo.

\section{Department of Romance Languages \\ Wake Forest University \\ Winston-Salem, USA}

\section{NOTAS}

1 Osvaldo Ảlvarez Guerrero, "Larra e Hispanoamérica. Larra y la generación de 1837," Revista de Occidente, número 50 (mayo 1967), pág. 231.

2 Ibid., págs. 236-37.

3 José Antonio Fernández de Castro, "Larra (1837-1937). En breve los 100 años," Revista Bimestre Cubana, 39 (1937), págs. 144-50; “Larra: Su formación intelectual,” Nosotros, 3 (1937), págs. 287-307; "Proyección de las ideas de Fígaro: Larra en Rizal," Universidad de la Habana, 3 (1937), págs. 80-96. José María Monner Sans, "Notas sobre Larra crítico literario," Nosotros, 3 (1937), págs. 169-75. Marcelo Olivari, Larra (Semblanza cruel), Buenos Aires: Ediciones Saeta, 1937. Eustaquio Tomé, Mariano José de Larra. Estudio crítico, Montevideo: Claudio García, 1938. Todos ellos forman parte de más de una treintena de trabajos sobre Larra escritos en Hispanoamérica hacia 1937.

${ }^{4}$ Ver las páginas 223-24 del artículo de José Antonio Oría. También Verdevoye, "A propos de certains articles signés 'Fígaro' parus dans le Mercurio de Valparaíso entre 1834 et 1837." En Melanges a la Memoire de Jean Sarrailh (Paris: Centre de Recherches de l'Institut d'Études Hispaniques, 1966), II, págs. 416-17.

${ }^{5}$ La Periodico Manía tampoco tuvo larga vida. Dejó de publicarse antes de diciembre de 1831. Ver Antonio Pradeiro, Indice cronológico de la prensa periódica del Uruguay, 1807-1852 (Montevideo: Universidad de la República Oriental del Uruguay, Facultad de Humanidades y Ciencias, 1962), pág. 43.

${ }^{6}$ Antonio Pradeiro, Indice, pág. 42.

${ }^{7}$ Ver el mencionado trabajo de Verdevoye.

${ }^{8}$ Como es sabido, el mismo Larra suprimió este párrafo en la edición de 1835. José Antonio Oría (página 238 del trabajo citado, nota 3) y Paul Verdevoye (Sarmiento éducateur et publiciste. Paris: Centre de Recherches de l'Institut d'Études Hispaniques [1963], Annexe I, págs. 479-82) se han referido ya a artículos de Larra publicados en el Río de la Plata. Oría cita sólo dos artículos, pero Verdevoye, en un trabajo bien documentado, da una lista por paises (Argentina, Chile, Uruguay) que comprende trabajos de I urra publicados en distintos periódicos desde 1834 a 1842 . Sin embargo, el mismo Verdevoye no cita el artículo "En este país" como publicado en Montevideo. Al parecer no consultó El Eco Oriental, puesto que no figura en su bibliografía de periódicos uruguayos (Sarmiento éducateur, pág. 610). 
${ }^{9}$ Son periódicos argentinos qưe también publicaron artículos de Larra. El Monitor, número 142 (6 de junio de 1834), reprodujo precisamente "En este país" (Sarmiento éducateur, pág. 479). Bien pudiera El Eco haberlo tomado de El Monitor, según las razones que da antes de reproducir el artículo de Larra, las cuales he citado más arriba.

Otra reimpresión de un artículo de Larra que no he visto citada en ninguna parte es la de "Las palabras," que él publicó en La Revista Española en 1834. Aparece al final de La viuda (San José: Talleres de la Minerva - de J.M. Menéndez, 1898), págs. 200-207. Se trata, claro está, de una traducción de la obra francesa de Octavio Feuillet. 